\title{
Racial Differences in Left Ventricular Filling Pressure Following Acute Aerobic Exercise Between Chinese and Caucasians
}

\author{
Peng Sun 1,3 (1) Huimin Yan $^{3} \cdot$ Sushant M. Ranadive ${ }^{3} \cdot$ Abbi D. Lane $^{2,3} \cdot$ Rebecca M. Kappus $^{2,3} \cdot$ Tracy Baynard $^{2,3}$. \\ Xiaodan Sun ${ }^{4}$. Shichang $\mathrm{Li}^{1}$ • Bo Fernhall ${ }^{2,3}$
}

Received: 12 July 2020 / Accepted: 26 September 2021 / Published online: 17 January 2022

(c) The Author(s) 2022

\begin{abstract}
Background Left ventricular filling pressure (LVFP) is an important early indicator of heart failure that is more prevalent in Caucasians than Chinese. Exercise-induced change in LVFP may provide more incremental information to assess diastolic function. But it was unknown whether there was difference in LVFP following acute exercise between Caucasians and Chinese.

Purpose The purpose of this study was to investigate the change of LVFP following an acute 45-min aerobic exercise in healthy Caucasian and Chinese individuals.

Methods Sixty participants (30 Caucasians and 30 Chinese, half was male, respectively) performed an acute bout of aerobic exercise at $70 \%$ of heart rate reserve. Hemodynamics, Left ventricle (LV) morphology and function parameters were measured at baseline, then at 30-min and 60-min post-exercise.

Results There was a similar LV ejection fraction, LV fraction shorten, lateral $E / e^{\prime}$ and lateral $e^{\prime}$ between Chinese and Caucasians at baseline. There was a significant race-by-time interaction in lateral $E / e^{\prime}$ and lateral $e^{\prime}$ between Chinese and Caucasians from pre-exercise to $30 \mathrm{~min}$ and $60 \mathrm{~min}$ after acute aerobic exercise. The $\Delta E / e^{\prime}$ was significant correlated with baseline systolic blood pressure.

Conclusion The change of LVFP was different between Chinese and Caucasians following acute aerobic exercise. The racial differences may be primarily caused by the changes of LV relaxation following exercise, baseline systolic blood pressure may also contribute to the differences.
\end{abstract}

Keywords Diastolic function $\cdot$ Left ventricular filling pressure $\cdot$ Racial differences

Peng Sun

psun@tyxx.ecnu.edu.cn

$\triangle$ Bo Fernhall

fernhall@uic.edu

1 Key Laboratory of Adolescent Health Assessment and Exercise Intervention, Ministry of Education, East China Normal University, Shanghai, People's Republic of China

2 College of Applied Health Sciences, University of Illinois at Chicago, Chicago, IL, USA

3 Department of Kinesiology and Community Health, University of Illinois at Urbana-Champaign, Champaign, IL, USA

4 Damujia Central Health Center, Weifang, Shandong, People's Republic of China

\section{Introduction}

Cardiovascular disease (CVD) is the main contributor to morbidity and mortality worldwide but there are interracial differences [18]. Caucasian (CA) population have significantly higher prevalence of CVD compared with their Chinese (CH) counterparts [46, 48, 49]. Previous studies have reported that the prevalence of coronary heart disease was $2.4 \%$ in CA and $0.9 \%$ in $\mathrm{CH}$ [16]. Left ventricle (LV) diastolic function, which often precedes systolic dysfunction [14], is an independent predictor of prognosis and adverse cardiac events [15], particularly in heart failure (HF), and $\mathrm{HF}$ is more prevalent in CA than in $\mathrm{CH}$ populations [4].

LV diastolic dysfunction (LVDD) is characterized by impaired diastolic relaxation and elevated LV filling pressure (LVFP) [9]. High baseline LVFP is also associated with a significantly increased all-cause mortality [1], and small 
changes in LVFP have been associated with significant clinical events and mortality [50]. Although most patients with HF had normal resting LVFP, during exercise, LVFP may rise rapidly [6]. Hence, the changes of LVFP caused by exercise may provide more incremental information to assess diastolic function. However, reported changes of LVFP following exercise have been variable and may influenced by exercise intensity, duration, and mode and recovery period after exercise [12]. To date, it is unknown if exercise at a pre-set duration, intensity and mode, produces different responses between $\mathrm{CH}$ and $\mathrm{CA}$ individuals.

The ratio of the early diastolic velocity on trans-mitral Doppler $(E)$ and the early diastolic velocity of mitral valve annulus obtained from tissue Doppler $\left(e^{\prime}\right)$ has been suggested as a reliable estimate of LVFP regardless of the cardiac rhythm and LV systolic function at rest [30], during or after exercise [22]. Elevated $E / e^{\prime}$ indicates a higher LVFP [26]. Most previous studies of exercise-induced changes of LVFP have focused on patients with LVDD, and found these patients had a significantly higher $E / e^{\prime}$ immediately post exercise compared to baseline [32]. In contrast, in healthy adults, $E / e^{\prime}$ does not change, or decreases slightly, immediately post exercise compared to baseline [31, 32]. Most studies have focused only on the immediately post-exercise period; however, the effect of exercise on LVFP may persist longer into recovery [12]. It is unclear whether evaluating changes of $E / e^{\prime}$ during a longer recovery period following exercise will provide additional useful information.

Therefore, the present investigation was conducted to investigate the change of LVFP at 30 and 60 min after an acute bout of aerobic exercise in healthy $\mathrm{CA}$ and $\mathrm{CH}$ men and women. In addition, we aimed to identify contributors to the changes of LVFP following exercise. The research hypothesis is that an acute bout of aerobic exercise can cause the change of LVFP, and the $E / e^{\prime}$ in the recovery period after exercise is higher in $\mathrm{CA}$ than in $\mathrm{CH}$.

\section{Materials}

\section{Subjects}

Healthy young $\mathrm{CA}$ and $\mathrm{CH}$ between the ages of 18 and 40 years were recruited in this study. Physical activity was assessed by the Lipid Research Clinics Questionnaire [2]. All subjects had normotensive blood pressure ( $\mathrm{SBP}<140 \mathrm{mmHg}, \mathrm{DBP}<90 \mathrm{mmHg}$ ), the BP guidelines for hypertension were based on the guideline at the time of data collection. To minimize the influence of hormones, the female subjects were tested during the early follicular phase of menstrual cycle [34]. This study was approved by the Institutional Review Board at the University of Illinois at Urbana-Champaign.

\section{Study Design}

All subjects were tested on two separate occasions with 48 h-2 weeks between each visit. Following the health history questionnaire, a peak aerobic capacity test was performed during the first visit. Hemodynamics and LV morphology and function parameters were measured while subjects were in the supine position pre-exercise. And then, an acute bout of aerobic exercise was performed using a treadmill. After completion of the treadmill exercise, the hemodynamics and LV morphology and function parameters were measured again $30 \mathrm{~min}$ and $60 \mathrm{~min}$ post exercise. All subjects were tested during the same time period (15:00-20:00) [23].

\section{Assessment of Peak Aerobic Capacity and Maximal Heart Rate}

The Bruce treadmill protocol was used to determine the peak aerobic capacity $\left(\mathrm{VO}_{2 \text { peak }}\right)$ [7]. Real-time heart rate (HR) was monitored with a Polar HR Monitor (Polar Electro, Woodbury, NY, USA). The Quark $b^{2}$ breath-by-breath metabolic system (Cosmed, Rome, Italy) was used to analyze expired gas [41]. The $\mathrm{HR}_{\max }$ was obtained to calculate the target HR during the exercise session [25].

\section{Aerobic Exercise Protocol}

After completion of 5-min warm-up exercise, a supervised treadmill exercise was performed at $70 \%$ of heart rate reserve (HRR). The Polar HR Monitor (Polar Electro, Woodbury, NY) was used to monitor Real-time HR.

\section{Measurement of Anthropometrics}

Height was measured using a stadiometer while weight was measured using an electronic scale. The ultrasonography (SSD- $\alpha 10$, Aloka, Tokyo, Japan) was used to measure the right common carotid artery intima-media thickness (IMT).

\section{Measurement of Hemodynamics}

The automated oscillometric cuff (HEM-907 XL; Omron, Shimane, Japan) was used to measure the right brachial artery blood pressure with the subjects in supine position. All brachial artery blood pressure measurements were recorded twice with a 1-min interval at rest. The average of two measurements was used for subsequent analysis. 


\section{Measurement of LV Morphology and Functions}

The ultrasonography (SSD- $\alpha 10$, Aloka, Tokyo, Japan) was used to obtained the echocardiographic measurements before and after exercise according to guidelines suggested by American Society of Echocardiography (ASE) and the European Association of Cardiovascular Imaging (EACVI) [30]. Left ventricular end-systolic and enddiastolic diameters and wall thickness were used to determined left ventricular dimensions. The diastolic wall strain $($ DWS $)=($ PWTs - PWTd $) /$ PWTs, where PWTs is the left ventricular posterior wall thickness at end-systole and PWTd is that at end-diastole. Left ventricular end-systolic volume (LVESV), left ventricular end-diastolic volume (LVEDV), left ventricular ejection fraction (EF) and fraction shorten (FS) were determined using a biplane Simpson method. The pulse-wave Doppler echography was used to determine early trans-mitral inflow velocity $(E)$ and deceleration time (DT). The tissue Doppler imaging was used to measure myocardial tissue lengthening velocity during early $\left(e^{\prime}\right)$ diastole. The $E / e^{\prime}$ ratio, which represents the LVFP, was also calculated [40]. Left ventricular mass index (LVMI) was calculated as follows: $\mathrm{LVMI}=$ left ventricular mass/body surface area.

\section{Statistical Analysis}

All data are presented as mean \pm SE. An independent samples $T$ test was used to analyze possible racial differences between Chinese and Caucasian subjects. A $2 \times 3$ ANCOVA was used to determine the effects of aerobic exercise on left ventricular systolic and diastolic function parameters between $\mathrm{CH}$ and $\mathrm{CA}$ subjects, controlling for age and brachial SBP and DBP. When a significant group-by-time interaction was detected, Bonferroni post hoc tests were used to analyze where the difference occurred. The strength of the linear relationship between the variables of interest was analyzed using Pearson correlation coefficient analysis. Statistical analyses were completed using SPSS 20.0 (SPSS Inc., Chicago, IL), and the significance level was $P<0.05$.

\section{Results}

Participant characteristics at baseline are presented in Table 1. Overall, $\mathrm{CH}$ participants were slightly older than their CA counterparts $(P<0.05)$. Furthermore, $\mathrm{CH}$ participants exhibited lower height, weight, $\mathrm{SV}, \mathrm{CO}$ and $\mathrm{BP}$ than $\mathrm{CH}(P<0.05)$. There were no differences in $\mathrm{BMI}, \mathrm{VO}_{2 \text { peak}}$, $\mathrm{HR}_{\text {rest }}, \mathrm{HR}_{\text {max }}, \mathrm{HR}_{\text {target }}, \mathrm{LVMI}$, or IMT between $\mathrm{CH}$ and $\mathrm{CA}$ groups.

Table 2 shows the data comparing the hemodynamic variables following exercise between $\mathrm{CH}$ and CA. Significant race-by-time interactions were found for brachial SBP and
Table 1 Baseline characteristics and resting hemodynamics

\begin{tabular}{lccc}
\hline Variables & $\mathrm{CH}(n=30)$ & $\mathrm{CA}(n=30)$ & $P$ value \\
\hline Age (years) & $28 \pm 4$ & $24 \pm 4$ & 0.000 \\
Height $(\mathrm{cm})$ & $165 \pm 7.3$ & $172 \pm 9.5$ & 0.003 \\
Weight $(\mathrm{kg})$ & $61.1 \pm 9.6$ & $67.9 \pm 9.1$ & 0.007 \\
$\mathrm{BMI}\left(\mathrm{kg} / \mathrm{m}^{2)}\right.$ & $22.3 \pm 2.6$ & $23.1 \pm 2.5$ & 0.236 \\
$\mathrm{VO}_{2 \text { peak }}(\mathrm{mL} / \mathrm{kg} / \mathrm{min})$ & $43.6 \pm 6.2$ & $46.9 \pm 9.6$ & 0.115 \\
$\mathrm{HR}_{\text {rest }}($ beats $/ \mathrm{min})$ & $68 \pm 11$ & $64 \pm 13$ & 0.148 \\
$\mathrm{HR}_{\text {max }}($ beats/min$)$ & $195 \pm 8$ & $193 \pm 10$ & 0.360 \\
$\mathrm{HR}_{\text {target }}(\mathrm{beats} / \mathrm{min})$ & $154 \pm 10$ & $157 \pm 8$ & 0.116 \\
$\mathrm{SV}(\mathrm{mL})$ & $64 \pm 15$ & $75 \pm 16$ & 0.009 \\
$\mathrm{CO}(\mathrm{L} / \mathrm{min})$ & $4.0 \pm 1.1$ & $4.8 \pm 1.2$ & 0.014 \\
$\mathrm{LVMI}\left(\mathrm{g} / \mathrm{m}^{2}\right)$ & $93.4 \pm 21.8$ & $96.7 \pm 24$ & 0.585 \\
$\mathrm{IMT}(\mathrm{mm})$ & $0.40 \pm 0.05$ & $0.40 \pm 0.05$ & 0.942 \\
$\mathrm{SBP}(\mathrm{mmHg})$ & $110 \pm 11$ & $120 \pm 9$ & 0.000 \\
$\mathrm{DBP}(\mathrm{mmHg})$ & $60 \pm 5.4$ & $66 \pm 5.6$ & 0.000 \\
\hline
\end{tabular}

Value are means $\pm \mathrm{SD}$

$n$ number, $C H$ Chinese, $C A$ Caucasian, $B M I$ body mass index, $H R_{\text {rest }}$ heart rate at rest, $H R_{\text {max }}$ maximal heart rate, $H R_{\text {target }}$ heart rate during exercise session, $S V$ stroke volume, $C O$ cardiac output, $L V M I$ left ventricular mass index, $I M T$ carotid artery intima-media thickness, $S B P$ systolic blood pressure, $D B P$ diastolic blood pressure

Table 2 The changes of hemodynamic parameters following exercise

\begin{tabular}{llcll}
\hline Variables & Race & At rest & $P 30$ & $P 60$ \\
\hline Brachial SBP (mmHg)*\# & CH & $110 \pm 11$ & $109 \pm 12$ & $107 \pm 10$ \\
& CA & $121 \pm 9$ & $118 \pm 14$ & $116 \pm 12$ \\
Brachial DBP (mmHg) $^{\#}$ & CH & $60 \pm 6$ & $61 \pm 5$ & $61 \pm 5$ \\
& CA & $66 \pm 6$ & $65 \pm 5$ & $63 \pm 5$ \\
HR (beats/min)*\# & CH & $68 \pm 13$ & $88 \pm 11$ & $76 \pm 14$ \\
& CA & $64 \pm 15$ & $79 \pm 15$ & $71 \pm 13$ \\
SV (mL) & CH & $64 \pm 15$ & $60 \pm 13$ & $60 \pm 15$ \\
& CA & $75 \pm 16$ & $67 \pm 14$ & $70 \pm 14$ \\
CO (L/min)*\# & CH & $4.0 \pm 1.1$ & $4.8 \pm 1.2$ & $4.4 \pm 1.2$ \\
& CA & $4.8 \pm 1.2$ & $5.1 \pm 1.5$ & $4.9 \pm 1.3$ \\
\hline
\end{tabular}

$C H$ Chinese, $C A$ Caucasian, $S B P$ systolic blood pressure, $D B P$ diastolic blood pressure, $H R$ heart rate, $S V$ stroke volume, $C O$ cardiac output

$* P<0.05$ time effect

${ }^{\#} P<0.05$ race-by-time interaction

DBP, HR and CO $(P<0.05)$, but there was no race-by-time interaction for $\mathrm{SV}$.

Table 3 shows the LV morphology and function parameters between $\mathrm{CH}$ and $\mathrm{CA}$ at baseline. The baseline IVSs, LVDs and LVESV, were slightly lower in the $\mathrm{CH}$ compared to the CA group $(P<0.05)$. The baseline $\mathrm{LV}$ systolic function parameters, such as LVEF, LVFS and diastolic function parameters, such as $E$, DT, lateral $e^{\prime}$, and lateral $E / e^{\prime}$, were not significantly different between the $\mathrm{CH}$ and $\mathrm{CA}$ groups. 
Table 3 Echocardiography parameters at rest

\begin{tabular}{lccc}
\hline Variables & CH $(n=30)$ & CA $(n=30)$ & $P$ value \\
\hline IVSd $(\mathrm{mm})$ & $8.53 \pm 1.34$ & $8.72 \pm 1.03$ & 0.530 \\
IVSs $(\mathrm{mm})$ & $11.03 \pm 1.73$ & $12.17 \pm 1.61$ & 0.010 \\
LVPWd $(\mathrm{mm})$ & $8.75 \pm 1.39$ & $8.17 \pm 1.20$ & 0.087 \\
LVPWs $(\mathrm{mm})$ & $13.09 \pm 1.61$ & $13.21 \pm 1.47$ & 0.776 \\
LVDd $(\mathrm{mm})$ & $47.63 \pm 5.90$ & $50.45 \pm 5.70$ & 0.062 \\
LVDs $(\mathrm{mm})$ & $29.63 \pm 3.99$ & $32.31 \pm 5.14$ & 0.028 \\
LVEDV $(\mathrm{mL})$ & $108.03 \pm 33.30$ & $122.38 \pm 32.73$ & 0.091 \\
LVESV $(\mathrm{mL})$ & $35.30 \pm 11.90$ & $43.55 \pm 17.09$ & 0.036 \\
LVEF $(\%)$ & $67.24 \pm 4.69$ & $65.51 \pm 6.34$ & 0.115 \\
LVFS $(\%)$ & $37.49 \pm 3.70$ & $36.39 \pm 4.77$ & 0.170 \\
$E(\mathrm{~cm} / \mathrm{s})$ & $86.41 \pm 12.98$ & $84.05 \pm 16.15$ & 0.470 \\
DT $(\mathrm{ms})$ & $174.66 \pm 31.57$ & $177.39 \pm 33.58$ & 0.674 \\
Lateral $e^{\prime}(\mathrm{cm} / \mathrm{s})$ & $15.12 \pm 2.76$ & $16.91 \pm 3.88$ & 0.057 \\
Lateral $E / e^{\prime}$ & $5.94 \pm 1.32$ & $5.42 \pm 1.71$ & 0.131 \\
\hline
\end{tabular}

IVSd diastolic interventricular septum thickness, IVSs systolic interventricular septum thickness, $L V P W d$ left ventricular diastolic posterior wall thickness, $L V P W s$ left ventricular systolic posterior wall thickness, $L V D d$ left ventricular diastolic diameter, $L V D s$ left ventricular systolic diameter, $L V E D V$ left ventricular end-diastolic volume, $L V E S V$ left ventricular end-systolic volume, $L V E F$ left ventricular ejection fraction, $L V F S$ left ventricular fractional shortening, $E$ early diastolic flow velocity of mitral flow, $D T$ E-wave deceleration time, lateral $e^{\prime}$ early diastolic velocity of the lateral mitral annulus, lateral $E / e^{\prime}$ the ratio between early diastolic flow velocity of mitral flow $(E)$ and early diastolic velocity of the lateral mitral annulus $\left(e^{\prime}\right)$

LV function is reportedly associated with age, HR, BP, and our data showed that age and resting BP were different between the $\mathrm{CA}$ and $\mathrm{CH}$. Hence, age and brachial SBP and DBP were used as the covariates to analyze the changes in LV function parameters following acute aerobic exercise in $\mathrm{CH}$ and $\mathrm{CA}$ (Fig. 1A-F). There were no race-by-time interactions for systolic function parameters, such as LVEF and LVFE (Fig. 1A, B). But there was a significant race-by-time interaction for lateral $E / e^{\prime}(F=12.03 ; P<0.05$; Fig. $1 \mathrm{~F})$, showing that the change in $E / e^{\prime}$ from pre-exercise to 30 and 60-min post-exercise was different between the groups. The lateral $E / e^{\prime}$ was sharply reduced in $\mathrm{CH}$ and increased in CA after exercise. These changes led to higher postexercise lateral $E / e^{\prime}$ for $\mathrm{CA}$ than for $\mathrm{CH}$. Furthermore, our data showed there also was a significant race-by-time interaction for lateral mitral annular $e^{\prime}$ velocity between groups following exercise $(F=23.55 ; P<0.05$; Fig. $1 \mathrm{E})$. Moreover, our data showed that lateral $E / e^{\prime}$ decreased sharply in $\mathrm{CH}$ subjects $30 \mathrm{~min}$ after exercise, but increased in CA. The change of mitral $E$ velocity or DT was similar between groups (Fig. 1C, D).

A Pearson correlation coefficient analysis was performed between the change values of lateral $E / e^{\prime}\left(\Delta E / e^{\prime}\right)$ from preexercise to 30-min post-exercise and baseline HR, SBP, $\mathrm{DBP}, \mathrm{VO}_{2 \text { peak }}$, DWS and BMI. Our data showed that there was a significant correlation between lateral $\Delta E / e^{\prime}$ and baseline SBP $(R=0.297, P=0.020$; Fig. 2B), but there was no significant correlation between lateral $\Delta E / e^{\prime}$ and baseline HR $(R=-0.021, P=0.875$; Fig. 2A $)$, DBP $(R=0.231$, $P=0.073 ;$ Fig. $2 \mathrm{C}), \mathrm{VO}_{2 \text { peak }}(R=0.238, P=0.064$; Fig. 2D), DWS ( $R=-0.105, P=0.421$; Fig. 2E) and BMI $(R=-0.169, P=0.192$; Fig. 2F).

\section{Discussion}

To our knowledge, this is the first study to focus on LVFP following an acute bout of aerobic exercise between $\mathrm{CH}$ and CA individuals. In the present study, we examined the changes in LV morphological and functional parameters from pre-exercise to $30 \mathrm{~min}$ and $60 \mathrm{~min}$ after exercise. Our primary findings were that (1) baseline lateral $E / e^{\prime}$, was similar between $\mathrm{CH}$ and CA individuals; (2) the change in lateral $E / e^{\prime}$ and lateral mitral annular $e^{\prime}$ velocity was different between $\mathrm{CH}$ and $\mathrm{CA}$ individuals from pre-exercise to 30and 60-min post-exercise. Particularly, at the 30th min of the recovery period, lateral $E / e^{\prime}$ decreased sharply in $\mathrm{CH}$ subjects, while the CA group increased compared to baseline; and (3) there was a significant correlation between lateral $\Delta E / e^{\prime}$ and baseline SBP.

Cardiovascular loading conditions, which is induced by the fluid shifts caused by exercise, directly influence cardiac function, which may affect the contractile properties of the myocardium [11]. However, the effect of exercise on LV systolic function is still controversial. LVEF is a valuable indicator of LV systolic function [20]. Several studies have found increased LVEF immediately after exercise compared to rest $[19,37]$, while another study showed that there was no change in LVEF at 15 min post exercise [36]. Middleton and colleagues [27] observed that increased exercise duration resulted in greater reductions in post-exercise LVEF. Our data showed that there was no significant change in either LVEF or LVFS at either $30 \mathrm{~min}$ or $60 \mathrm{~min}$ after 45-min aerobic exercise, suggesting $\mathrm{CH}$ and $\mathrm{CA}$ subjects exhibited similar LV systolic function following acute aerobic exercise.

LV diastolic function is an important early indicator of myocardial dysfunction often present in various heart conditions, and often precedes alterations in systolic function $[14,40]$. Elevated LVFP is thought to be the direct causes of impairment of LV diastolic function [21]. Exercise-induced change in LVFP may provide more incremental information to assess diastolic function $[6,8,13]$ at rest $[30]$ and after exercise $[3,8]$. Noninvasive echocardiographic tissue Doppler assessment $\left(E / e^{\prime}\right)$ in response to exercise has been proposed as a useful parameter to assess LVFP and LV diastolic function [10, 38]. The effects of exercise on LVFP are controversial. Previous investigations have shown that the E/e' ratio, an accurate 
Fig. 1 LV systolic and diastolic echocardiographic parameters at rest, $30 \mathrm{~min}(\mathrm{P} 30)$ and $60 \mathrm{~min}$ post exercise (P60) in Chinese $(\mathrm{CH})$ and Caucasians (CA). A $L V E F$ left ventricular ejection fraction; B $L V F S$ left ventricular fraction shorten; $\mathbf{C} E$ early diastolic flow velocity of mitral flow; D DT E-wave deceleration time; E lateral $e^{\prime}$ early diastolic velocity of the lateral mitral annulus; $\mathbf{F}$ lateral E/e' the ratio between early diastolic flow velocity of mitral flow $(E)$ and early diastolic velocity of the lateral mitral annulus $\left(e^{\prime}\right)$. $* P<0.05$ for the time effect; ${ }^{\#} P<0.05$ for the race-by-time interaction
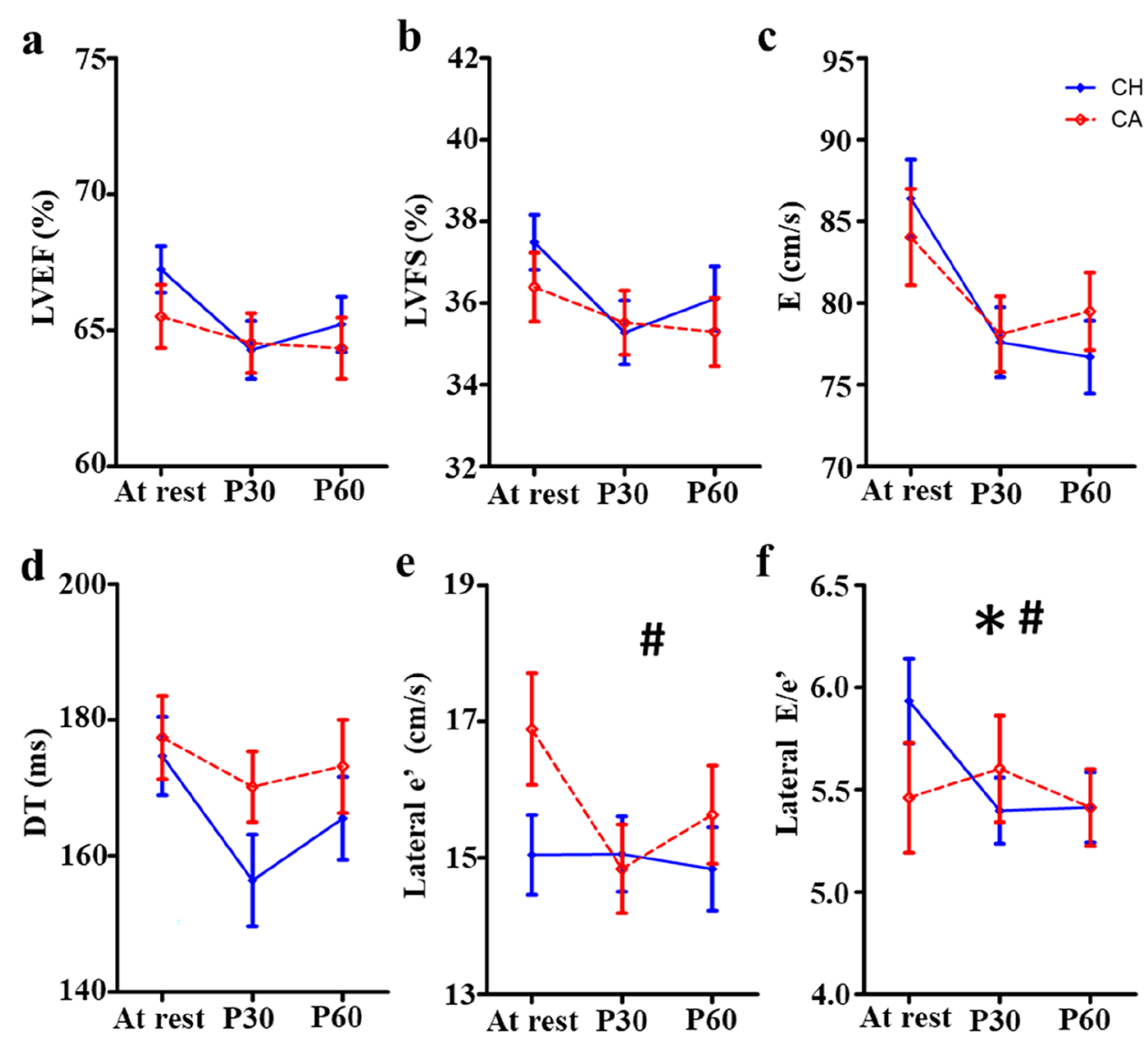

f

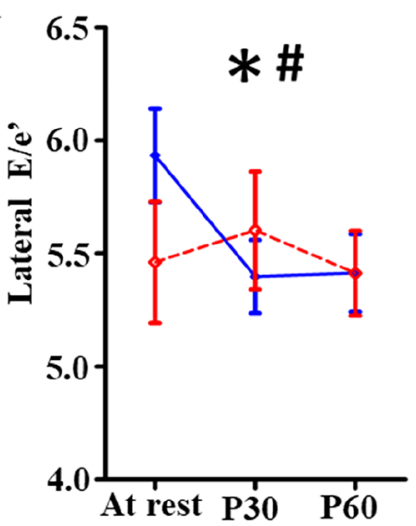

estimator of LVFP, significantly increased immediately after exercise $[36,42,44]$, while other studies found there was no any change [19, 37]. Shave et al. suggested, unlike systolic function, temporary reductions in diastolic function were more readily triggered by short and high-intensity exercise [39]. Our data showed that the change in lateral $E / e^{\prime}$ was significantly different between $\mathrm{CH}$ and $\mathrm{CA}$ subjects from pre-exercise to $30 \mathrm{~min}$ and $60 \mathrm{~min}$ after 45 -min aerobic exercise. Of note is the fact that $\mathrm{CH}$ had a sharp decrease at $30 \mathrm{~min}$ post exercise, while CA subjects increased when compared to the baseline values. These changes led to higher post-exercise LVFP for $\mathrm{CA}$ than for $\mathrm{CH}$, which may be associated with a higher incidence of CVD in CA. The reduction of E/ $e^{\prime}$ exhibits the ability of the heart to fill at lower pressures during the recovery period after exercise. Exercise-induced LVFP changes are likely to be caused by alteration in myocardial relaxation [5, 12]. Consistent with this, our data showed that the changes of lateral mitral annular $e^{\prime}$ velocity, which reflect $\mathrm{LV}$ relaxation, were also different between $\mathrm{CH}$ and $\mathrm{CA}$ following exercise, while the changes of mitral $E$ velocity were similar between the races. This suggests the different change of LVFP between races may be caused by disproportionate changes in mitral annular $e^{\prime}$ velocity and mitral $E$ velocity between $\mathrm{CH}$ and $\mathrm{CA}$ subjects following exercise.

As previously reported, LV diastolic function and LVFP were associated with HR [39], hemodynamics [5, 28, 29], exercise capacity [17, 24], LV deformation [33, 43, 45] and BMI [35, 47]. We also investigated whether baseline HR, $\mathrm{BP}$, aerobic capacity, DWS, and BMI might produce different influences on $\Delta E / e^{\prime}$ between races. Our data showed that there was no significant correlation between $\Delta E / e^{\prime}$ and baseline HR, DBP, $\mathrm{VO}_{2 \text { peak }}$, DWS and BMI, respectively, following exercise. The $\Delta E / e^{\prime}$ was significantly correlated with baseline SBP, suggesting SBP may contribute to the change of lateral $E / e^{\prime}$ following exercise. The lower baseline SBP can produce a greater exercise-induced drop in $E / e^{\prime}$, but the exact mechanism is unclear.

\section{Limitations}

The study was conducted in a population of healthy adults and would be more valuable in a population with cardiovascular disease. Furthermore, we measured the LV morphological and functional parameters only at pre-exercise, 
Fig. 2 The correlations between $\Delta E / e^{\prime}$ and baseline $\mathrm{HR}(\mathbf{A})$, $\operatorname{SBP}(\mathbf{B}), \operatorname{DBP}(\mathbf{C}), \mathrm{VO}_{2 \text { peak }}$ (D), DWS (E), and BMI $(\mathbf{F})$ in Chinese $(\mathrm{CH})$ and Caucasians (CA). $\Delta E / e^{\prime}$ the change values of lateral $E / e^{\prime}$ from pre to 30 min post exercise, $H R$ heart rate, $S B P$ systolic blood pressure, $D B P$ diastolic blood pressure, $V O_{2 \text { peak }}$ peak aerobic capacity, $D W S$ diastolic wall strain, $B M I$ body mass index
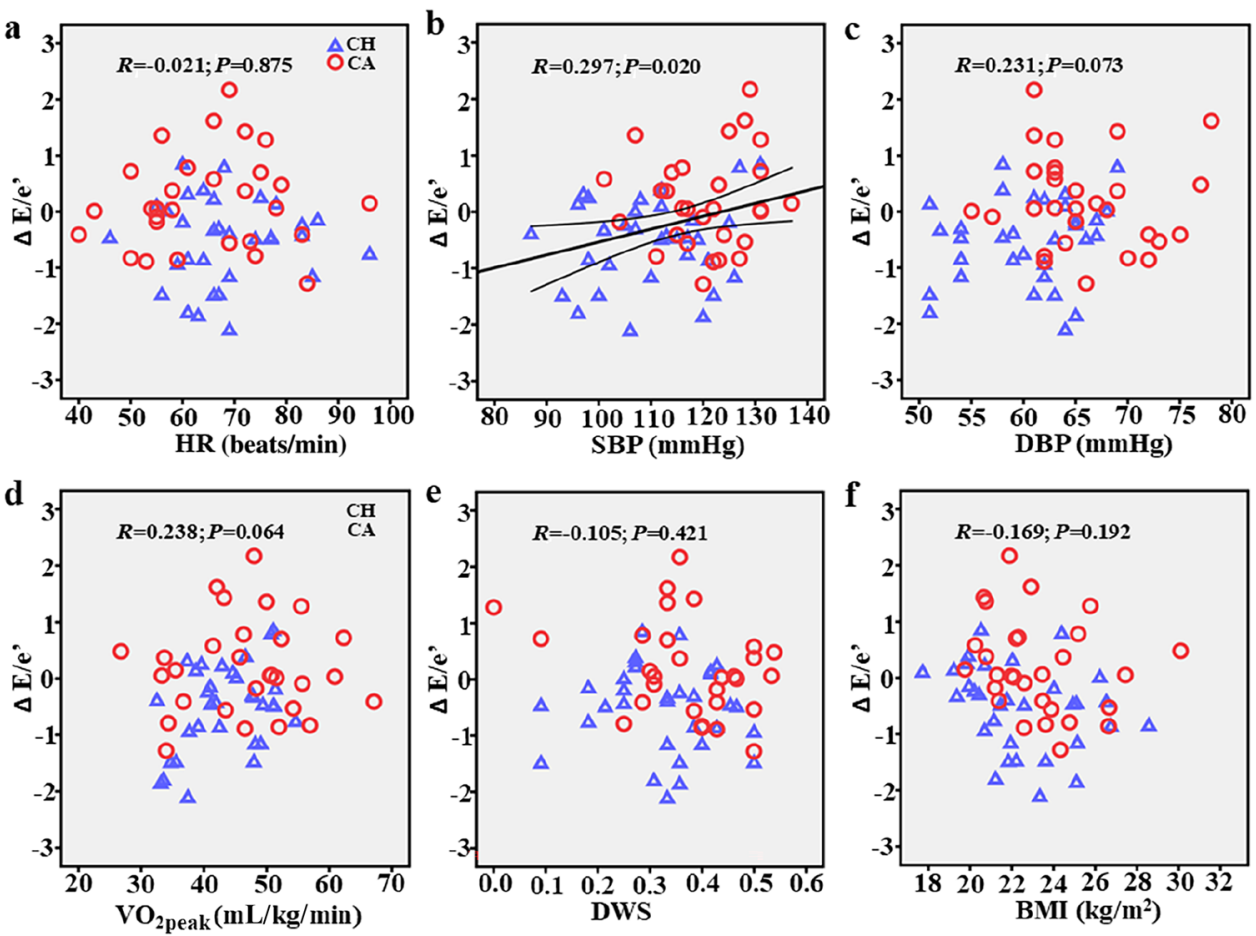

$30 \mathrm{~min}$ and $60 \mathrm{~min}$ post exercise. The values from immediately after exercise or longer than 60 min during exercise recovery would provide more information to estimate LVFP and LV diastolic function.

\section{Conclusion}

In our study, we demonstrated racial differences in the changes of lateral $E / e^{\prime}$ ratio, an estimate of LVFP, following acute aerobic exercise. In addition, we suggested that this racial difference might be primarily caused by the changes of lateral mitral annular $e^{\prime}$ velocity, reflecting $\mathrm{LV}$ relaxation, following exercise, and baseline SBP might contribute to the differences, lower baseline SBP could produce a greater exercise-induced drop in $E / e^{\prime}$. Moreover, although the exact potential mechanism for the racial differences on CVD is not known, our findings suggest that exercise-induced changes in myocardial function may yield future insight regarding racial differences in the development of CVD.

Funding This study was funded by the National Institute of Health of USA (1R01HL093249-01A1), and National Education Science Planning Program of China (BLA170225).

Availability of data and materials Not applicable.

Code availability Not applicable.

\section{Declarations}

Conflict of interest None of the authors have any personal or financial conflict of interest. All authors take responsibility for all aspects of the reliability and freedom from bias of the data presented and their discussed interpretation.

Ethics approval Not applicable.

Consent to participate Not applicable.

Consent to publish Not applicable.

Open Access This article is licensed under a Creative Commons Attribution 4.0 International License, which permits use, sharing, adaptation, distribution and reproduction in any medium or format, as long as you give appropriate credit to the original author(s) and the source, provide a link to the Creative Commons licence, and indicate if changes were made. The images or other third party material in this article are included in the article's Creative Commons licence, unless indicated otherwise in a credit line to the material. If material is not included in the article's Creative Commons licence and your intended use is not permitted by statutory regulation or exceeds the permitted use, you will need to obtain permission directly from the copyright holder. To view a copy of this licence, visit http://creativecommons.org/licenses/by/4.0/.

\section{References}

1. Abudiab MM, Chebrolu LH, Schutt RC, Nagueh SF, Zoghbi WA. Doppler echocardiography for the estimation of LV filling pressure in patients with mitral annular calcification. JACC Cardiovasc Imaging. 2017;10(12):1411-20. 
2. Ainsworth BE, Jacobs DR Jr, Leon AS. Validity and reliability of self-reported physical activity status: the Lipid Research Clinics questionnaire. Med Sci Sports Exerc. 1993;25(1):92-8.

3. Asrar ul Haq M, Mutha V, Lin T, Profitis K, Tuer Z, Lim K, Hare $\mathrm{DL}$, Wong C. Left ventricular torsional dynamics post exercise for LV diastolic function assessment. Cardiovasc Ultrasound. 2014;12:8.

4. Bahrami H, Kronmal R, Bluemke DA, Olson J, Shea S, Liu K, Burke GL, Lima JA. Differences in the incidence of congestive heart failure by ethnicity: the multi-ethnic study of atherosclerosis. Arch Intern Med. 2008;168(19):2138-45.

5. Berlot B, Moya Mur JL, Jug B, Rodríguez Muñoz D, Megias A, Casas Rojo E, Fernández-Golfín C, Zamorano JL. Effect of diastolic dysfunction on intraventricular velocity behavior in early diastole by flow mapping. Int J Cardiovasc Imaging. 2019;35(9):1627-36.

6. Borlaug BA, Nishimura RA, Sorajja P, Lam CS, Redfield MM. Exercise hemodynamics enhance diagnosis of early heart failure with preserved ejection fraction. Circ Heart Fail. 2010;3(5):588.

7. Bruce RA. Methods of exercise testing. Step test, bicycle, treadmill, isometrics. Am J Cardiol. 1974;33(6):715-20.

8. Burgess MI, Jenkins C, Sharman JE, Marwick TH. Diastolic stress echocardiography: hemodynamic validation and clinical significance of estimation of ventricular filling pressure with exercise. $\mathrm{J}$ Am Coll Cardiol. 2006;47(9):1891-900.

9. Chang HC, Cheng HM. P wave peak time: a time window to evaluate left ventricular diastolic function. J Clin Hypertens. 2019;21(5):616-7.

10. Choi S, Shin JH, Park WC, Kim SG, Shin J, Lim YH, Lee Y. Two distinct responses of left ventricular end-diastolic pressure to leg-raise exercise in euvolemic patients with exertional dyspnea. Korean Circ J. 2016;46(3):350-64.

11. Coyle EF. Cardiovascular drift during prolonged exercise and the effects of dehydration. Int J Sports Med. 1998;19(Suppl 2):S121-4.

12. Donaldson JA, Wiles JD, Coleman DA, Papadakis M, Sharma $\mathrm{R}$, O'Driscoll JM. Left ventricular function and cardiac biomarker release-the influence of exercise intensity, duration and mode: a systematic review and meta-analysis. Sports Med. 2019;49(8):1275-89.

13. Dorfs S, Zeh W, Hochholzer W, Jander N, Kienzle RP, Pieske B, Neumann FJ. Pulmonary capillary wedge pressure during exercise and long-term mortality in patients with suspected heart failure with preserved ejection fraction. Eur Heart J. 2014;35(44):3103-12.

14. Dougherty AH, Naccarelli GV, Gray EL, Hicks CH, Goldstein RA. Congestive heart failure with normal systolic function. Am J Cardiol. 1984;54(7):778-82.

15. Fontes-Carvalho R, Azevedo AI, Sampaio F, Teixeira M, Bettencourt N, Campos L, Gonçalves FR, Ribeiro VG, Azevedo A, LeiteMoreira A. The effect of exercise training on diastolic and systolic function after acute myocardial infarction a randomized study. Medicine. 2015;94(36):e1450.

16. Francis DK, Bennett NR, Ferguson TS, Hennis AJM, Wilks RJ, Harris EN, MacLeish MMY, Sullivan LW; US Caribbean Alliance for Health Disparities Research Group. Disparities in cardiovascular disease among Caribbean populations: a systematic literature review. BMC Public Health. 2015;15:828.

17. Guazzi M, Myers J, Peberdy MA, Bensimhon D, Chase P, Arena R. Cardiopulmonary exercise testing variables reflect the degree of diastolic dysfunction in patients with heart failure-normal ejection fraction. J Cardiopulm Rehabil Prev. 2010;30(3):165-72.

18. Gurwitz JH, Magid DJ, Smith DH, Hsu G, Sung SH, Allen LA, McManus DD, Goldberg RJ, Go AS; Cardiovascular Research Network PRESERVE Study. The complex relationship of race to outcomes in heart failure with preserved ejection fraction. Am J Med. 2015;128(6):591-600.
19. Ha JW, Lulic F, Bailey KR, Pellikka PA, Seward JB, Tajik AJ, Oh JK. Effects of treadmill exercise on mitral inflow and annular velocities in healthy adults. Am J Cardiol. 2003;91(1):114-5.

20. He J, Yang L. Value of three-dimensional speckle-tracking imaging in detecting left ventricular systolic function in patients with dilated cardiomyopathy. Echocardiography. 2019;36(8):1492-5.

21. Hees PS, Fleg JL, Dong SJ, Shapiro EP. MRI and echocardiographic assessment of the diastolic dysfunction of normal aging: altered LV pressure decline or load? Am J Physiol Heart Circ Physiol. 2004;286(2):H782-8.

22. Holland DJ, Prasad SB, Marwick TH. Prognostic implications of left ventricular filling pressure with exercise. Circ Cardiovasc Imaging. 2010;3(2):149-56.

23. Jones H, George K, Edwards B, Atkinson G. Effects of time of day on post-exercise blood pressure: circadian or sleep-related influences? Chronobiol Int. 2008;25(6):987-98.

24. Jung MH, Ihm SH, Lee DH, Chung WB, Jung HO, Youn HJ. Prehypertension is associated with early complications of atherosclerosis but not with exercise capacity. Int J Cardiol. 2017;227:387-92.

25. McConnell TR. Practical considerations in the testing of VO2max in runners. Sports Med. 1988;5(1):57-68.

26. Michelsen MM, Pena A, Mygind ND, Høst N, Gustafsson I, Hansen PR, Hansen HS, Kastrup J, Prescott E. Overlap between angina without obstructive coronary artery disease and left ventricular diastolic dysfunction with preserved ejection fraction. PLoS One. 2019;14(5):e0216240.

27. Middleton N, Shave R, George K, Whyte G, Hart E, Atkinson G. Left ventricular function immediately following prolonged exercise: a meta-analysis. Med Sci Sports Exerc. 2006;38(4):681-7.

28. Milan A, Puglisi E, Magnino C, Naso D, Abram S, Avenatti E, Rabbia F, Mulatero P, Veglio F. Left atrial enlargement in essential hypertension: role in the assessment of subclinical hypertensive heart disease. Blood Press. 2012;21(2):88-96.

29. Miyahara T, Yokota M, Sobue T, Nishinaka Y, Iwase M, Ukai M, Watanabe M, Kodama Y, Matsunami T, Koide M. Abnormal postexercise systolic blood pressure response is a good indicator of impaired left ventricular filling during supine cycle ergometer exercise in patients with coronary artery disease. Jpn Circ J. 1993;57(6):480-8.

30. Nagueh SF, Smiseth OA, Appleton CP, Byrd BF 3rd, Dokainish H, Edvardsen T, Flachskampf FA, Gillebert TC, Klein AL, Lancellotti P, Marino P, Oh JK, Popescu BA, Waggoner AD. Recommendations for the evaluation of left ventricular diastolic function by echocardiography: an update from the American Society of Echocardiography and the European Association of Cardiovascular Imaging. J Am Soc Echocardiogr. 2016;29(4):277-314.

31. Nagueh SF, Sun H, Kopelen HA, Middleton KJ, Khoury DS. Hemodynamic determinants of the mitral annulus diastolic velocities by tissue Doppler. J Am Coll Cardiol. 2001;37(1):278-85.

32. Narayanan M, Bamba A, Liu S, Naqvi TZ. Impaired left and right ventricular systolic and diastolic function in response to exercise in patients with diastolic dysfunction. Echocardiography. 2016;33(8):1209-18.

33. Ohtani T, Mohammed SF, Yamamoto K, Dunlay SM, Weston SA, Sakata Y, Rodeheffer RJ, Roger VL, Redfield MM. Diastolic stiffness as assessed by diastolic wall strain is associated with adverse remodelling and poor outcomes in heart failure with preserved ejection fraction. Eur Heart J. 2012;33(14):1742-9.

34. Ounis-Skali N, Mitchell GF, Solomon CG, Solomon SD, Seely EW. Changes in central arterial pressure waveforms during the normal menstrual cycle. J Investig Med. 2006;54(6):321-6.

35. Rueda-Ochoa OL, Smiderle-Gelain MA, Rizopoulos D, Dhana K, van den Berge JK, Echeverria LE, Ikram MA, Deckers JW, Franco OH, Kavousi M. Risk factors for longitudinal changes in left ventricular diastolic function among women and men. Heart. 2019;105(18):1414-22. 
36. Rundqvist L, Engvall J, Faresjo M, Blomstrand P. Left ventricular diastolic function is enhanced after peak exercise in endurancetrained adolescents as well as in their non-trained controls. Clin Physiol Funct Imaging. 2018;38(6):1054-61.

37. Schiano-Lomoriello V, Santoro C, de Simone G, Trimarco B, Galderisi M. Diastolic bicycle stress echocardiography: Normal reference values in a middle age population. Int J Cardiol. 2015;191(181):3.

38. Sharifov OF, Gupta H. What is the evidence that the tissue Doppler index E/e' reflects left ventricular filling pressure changes after exercise or pharmacological intervention for evaluating diastolic function? a systematic review. J Am Heart Assoc. 2017;6(3):e004766.

39. Shave R, Oxborough D. Exercise-induced cardiac injury: evidence from novel imaging techniques and highly sensitive cardiac troponin assays. Prog Cardiovasc Dis. 2012;54(5):407-15.

40. Shigematsu K, Iwashita K, Mimata R, Owaki R, Totoki T, Gohara A, Okawa J, Higashi M, Yamaura K. Preoperative left ventricular diastolic dysfunction is associated with pulmonary edema after carotid endarterectomy. Neurol Med Chir. 2019;59(8):299.

41. Sun P, Yan H, Ranadive SM, Lane AD, Kappus RM, Bunsawat K, Baynard T, Hu M, Li S, Fernhall B. Autonomic recovery is delayed in Chinese compared with Caucasian following treadmill exercise. PLoS One. 2016;11(1):e0147104.

42. Takagi T, Takagi A, Yoshikawa J. Elevated left ventricular filling pressure estimated by $\mathrm{E} / \mathrm{E}^{\prime}$ ratio after exercise predicts development of new-onset atrial fibrillation independently of left atrial enlargement among elderly patients without obvious myocardial ischemia. J Cardiol. 2014;63(2):128-33.

43. Takagi T, Takagi A, Yoshikawa J. Low diastolic wall strain is associated with raised post-exercise $\mathrm{E} / \mathrm{E}^{\prime}$ ratio in elderly patients without obvious myocardial ischemia. J Echocardiogr. 2014;12(3):106-11.
44. Takagi T, Yoshikawa J. Diastolic stress echocardiography in Japanese elderly patients: prevalence and features of patients with elevated left ventricular filling pressure after treadmill stress. J Echocardiogr. 2011;9(1):17-23.

45. Takeda Y, Sakata Y, Higashimori M, Mano T, Nishio M, Ohtani T, Hori M, Masuyama T, Kaneko M, Yamamoto K. Noninvasive assessment of wall distensibility with the evaluation of diastolic epicardial movement. J Card Fail. 2009;15(1):68-77.

46. Vitalis A, Lip GY, Kay M, Vohra RK, Shantsila A. Ethnic differences in the prevalence of peripheral arterial disease: a systematic review and meta-analysis. Expert Rev Cardiovasc Ther. 2017;15(4):327-38.

47. Yang MC, Liu HK, Su YT, Tsai CC, Wu JR. Serum apoptotic marker M30 is positively correlated with early diastolic dysfunction in adolescent obesity. PLoS One. 2019;14(5):e0217429.

48. Zemrak F, Ambale-Venkatesh B, Captur G, Chrispin J, Chamera E, Habibi M, Nazarian S, Mohiddin SA, Moon JC, Petersen SE, Lima JAC, Bluemke DA. Left atrial structure in relationship to age, sex, ethnicity, and cardiovascular risk factors MESA (multi-ethnic study of atherosclerosis). Circ Cardiovasc Imaging. 2017;10(2):e005379.

49. Zheng Y, Stein R, Kwan T, Yu C, Kwan J, Chen SL, Hu DY. Evolving cardiovascular disease prevalence, mortality, risk factors, and the metabolic syndrome in China. Clin Cardiol. 2009;32(9):491-7.

50. Zile MR, Bennett TD, El Hajj S, Kueffer FJ, Baicu CF, Abraham WT, Bourge RC, Stevenson LW. Intracardiac pressures measured using an implantable hemodynamic monitor relationship to mortality in patients with chronic heart failure. Circ Heart Fail. 2017;10(1):e003594. 